See discussions, stats, and author profiles for this publication at: https://www.researchgate.net/publication/331719625

\title{
The Effect of Contextual Risk Factors on the Effectiveness of Brief Personality- Targeted Interventions for Adolescent Alcohol Use and Misuse: A Cluster- Randomized Trial
}

Article in Alcoholism Clinical and Experimental Research · March 2019

DOI: 10.1111/acer.14016

CITATION

1

4 authors, including:

(8)

Hanie Edalati

Université de Montréal

19 PUBLICATIONS 120 CITATIONS

SEE PROFILE

Patricia Conrod

Université de Montréal

324 PUBLICATIONS 10,324 CITATIONS

SEE PROFILE

Some of the authors of this publication are also working on these related projects:

Pro-Venture: Understanding the role of cannabis in the development of prodrome psychosis View project

Project Preventure View project
READS

175

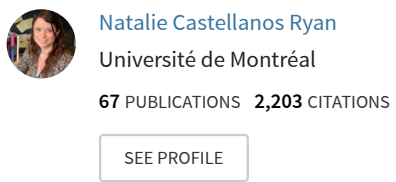


DR. HANIE EDALATI (Orcid ID : 0000-0002-4227-8890)

Article type : Original Research Article

\section{The Effect of Contextual Risk Factors on the Effectiveness of Brief Personality- targeted Interventions for Adolescent Alcohol Use and Misuse: A Cluster}

\section{Randomised Trial}

Hanie Edalati, PhD ${ }^{\text {a,b }}$, Mohammad H. Afzali, PhD ${ }^{\text {a,b }}$, Natalie Castellanos-Ryan, PhD $^{c}$, Patricia J. Conrod, $\mathrm{PhD}^{\mathrm{a}, \mathrm{b}, \mathrm{d} *}$
a. Research Center, Centre Hospitalier Universitaire Sainte-Justine, 3175 Chemin de la Côte Sainte-Catherine, Montréal, Québec H3T 1C5, Canada
b. Department of Psychiatry, Université de Montréal, Pavillon Roger-Gaudry, 2900 boulevard Édouard-Montpetit, Montréal, Québec H3T 1J4, Canada
c. École de Psychoéducation, Université de Montréal, Pavillon Marie-Victorin, 90 avenue Vincent-d'Indy, Outremont, Québec H2V 2S9, Canada
d. National Addiction Centre, Institute of Psychiatry, Psychology \& Neuroscience (IoPPN), Addiction Sciences Building, 4 Windsor Walk, Denmark Hill, London SE5 8BB, United Kingdom

This article has been accepted for publication and undergone full peer review but has not been through the copyediting, typesetting, pagination and proofreading process, which may lead to differences between this version and the Version of Record. Please cite this article as doi: 10.1111/acer.14016

This article is protected by copyright. All rights reserved. 
* Corresponding author: Dr. Patricia J. Conrod

Professeure, Department of Psychiatry, University of Montreal

Chercheur Boursier Senior, FRSQ; Fondation Julien/Marcelle et Jean Coutu Chair in

Social and Community Pediatrics

CHU Sainte-Justine Research Center

3175 Côte-Ste-Catherine, Montréal, QC, H3T 1C5

tel: $5143454931($ ext 4051)

Email: patricia.conrod@umontreal.ca

Running head: Contextual Risk Factors in Prevention

Declarations of competing interest: The authors declare no potential conflicts of interest with respect to the research, authorship, and/or publication of this article.

Clinical trial registration information: Personality-Targeted Interventions for Adolescent Alcohol Misuse, URL: http://www.clinicaltrials.gov, unique identifier: NCT00344474.

Funding: This investigation was supported by a research grant and fellowship (20032008) from Action on Addiction, registered charity number 1007308. H. Edalati is supported through postdoctoral fellowship by the CHU Sainte-Justine Foundation and Canadian Institutes of Health Research (CIHR). M. H. Afzali is supported through postdoctoral fellowship by the CHU Sainte-Justine Foundation. N. Castellanos-Ryan is

This article is protected by copyright. All rights reserved. 
supported by fellowships from the Ministère de l'Éducation, du Loisir et du Sport du Québec, and the Fonds de Recherche en Santé du Québec. P. J. Conrod is supported through a senior research fellowship from the Fonds de recherche du Québec - Santé (FRQS), and the following Research Chair: Fondation Julien/Marcelle et Jean Coutu en Pediatrie Sociale en Communaute de l' Universite de Montreal.

\begin{abstract}
Background. A range of school-based prevention programmes has been developed and used to prevent, delay, or reduce alcohol use among adolescents. Most of these programmes have been evaluated at the community-level impact. However, the effect of contextual risk factors has rarely been considered in the evaluation of these programmes. The aim of this study was to investigate the potential moderating effects of two important contextual risk factors (i.e., socioeconomic status and peer victimisation) on the effectiveness of the school-based personality-targeted interventions (Preventure programme) in reducing adolescent alcohol use over a two-year period using a clusterrandomised trial.
\end{abstract}

Methods. High-risk adolescents were identified using personality scores on the Substance Use Risk Profile Scale (Woicik et al., 2009) and randomised to intervention and control groups. Two 90-minute CBT-based group sessions targeted one of four personality risk profiles, Anxiety-Sensitivity, Hopelessness, Impulsivity, or Sensation Seeking. Multilevel Linear Modelling of alcohol use, binge drinking and drinking-related

This article is protected by copyright. All rights reserved. 
harm was conducted to assess the moderating effect of baseline peer victimisation and socioeconomic status.

Results. Results indicated that the Preventure programme was equally beneficial to all adolescents, regardless of socioeconomic status and victimisation history, in terms of their alcohol outcomes and related harm. Receiving the intervention was additionally beneficial for adolescents reporting peer victimisation regarding their alcohol-related harm compared to non-victimised youth $(\beta=-.29$, S.E.=.11, $p=.014)$.

Conclusions. Findings suggest that the content of personality-targeted interventions is beneficial for all high-risk youth regardless of their socioeconomic status or experience of peer victimisation. The current study suggests that using targeted approaches, such as targeting underlying personality risk factors, may be the most appropriate substance use prevention strategy for high-risk youth, as it is beneficial for all high-risk youth regardless of their contextual risk factors.

Key words: School-based Alcohol Use Prevention; Personality-targeted Interventions; Socioeconomic Status; Peer Victimisation; Adolescents.

This article is protected by copyright. All rights reserved. 


\section{Introduction}

A range of school-based prevention programmes has been developed and used to prevent, delay, or reduce alcohol use among adolescents (e.g., Cuijpers 2002, Foxcroft, Tsertsvadze 2011, Tobler, Roona et al. 2000). Most of these intervention programmes target all students, regardless of their environmental context or level of risk for alcohol and drug use, and are based on delivering generic intervention components (e.g., knowledge and skills) that are suitable for general populations of adolescents (i.e., universal approaches) (e.g., Botvin, Baker et al. 1990, Ellickson, Bell 1990). However, several literature reviews and meta-analyses have shown that most universal approaches have small or no effects in reducing substance use among adolescents (e.g., Cuijpers 2002, Foxcroft, Tsertsvadze 2011, Tobler, Roona et al. 2000). In particular, adolescents who are most at risk of transitioning to substance use disorders, and those who have already started using substances may not benefit from these approaches (Gottfredson, Wilson 2003). In response, selective and indicated intervention programmes target the potential risk factors for substance misuse in at-risk adolescents (e.g. Dishion, Andrews 1995, Harrington, Donohew 1997). These programmes are more beneficial for adolescents with individual risk factors (e.g., high-risk personality profiles) and/or contextual/environmental risk factors (e.g., living in vulnerable context, poverty (Conrod 2016, Dishion, Andrews 1995, Harrington, Donohew 1997, Edalati, Conrod 2017)).

Preventure is a selective substance use prevention programme which was designed to target four personality risk factors for substance misuse: Hopelessness, Anxiety Sensitivity, Impulsivity, and Sensation Seeking (Conrod 2016). Evidence from cross-sectional and longitudinal studies have shown association between these

This article is protected by copyright. All rights reserved. 
personality risk factors to early initiation and escalation of substance misuse in adolescents (Conrod, Nikolaou 2016). The Preventure programme has been evaluated in eight randomised trials in Canada, United Kingdom, and Australia. Findings have indicated that this programme is successful in reducing the rates of illicit drug use and binge drinking by approximately 50\% in high-risk adolescents with the effects lasting for up to three years (for a review of Preventure trials and their results, see Conrod 2016). In addition, these interventions were associated with a $25 \%$ reduced likelihood of transitioning to significant mental health problems, such as anxiety, depression, suicidal ideation, and conduct problems (O'Leary-Barrett, Castellanos-Ryan et al. 2016). Two recent studies involving secondary analyses of Preventure trials reported that the programme is particularly effective for youth with more significant risk profiles, such as youth reporting clinically significant levels of externalising problems at baseline (PerrierMenard, Castellanos-Ryan et al. 2017) and youth attending vocational schools in the Netherlands (Lammers, Goossens et al. 2017). However, it is not clear whether additional contextual risk factors, such as socioeconomic status (SES) and peer victimisation, moderate intervention outcomes. Since contextual risk factors, such as SES and peer victimisation, increase the risk of early alcohol and substance misuse among adolescents (e.g., Maniglio 2017, Hanson, Chen 2007), it is probable that they also influence the effectiveness of substance use prevention programmes. Most school-based intervention programmes have been evaluated at the community-level impact, whereas, the effect of contextual risk factors has rarely been considered in the evaluation of these programmes for alcohol use outcomes. The aim of this study was to address this gap in the literature by examining the impact of SES and peer victimisation on the effectiveness of

This article is protected by copyright. All rights reserved. 
personality-targeted interventions (i.e., Preventure programme) against adolescent alcohol use outcomes.

\section{Effects of Socioeconomic Status on Alcohol Use Prevention programmes}

A growing number of studies has examined the associations between SES and adolescent alcohol consumption (Hanson, Chen 2007). A systematic review of studies across different countries has indicated that the association between SES and adolescent alcohol use is not clear and requires additional studies to elucidate this relationship in different countries (Hanson, Chen 2007). Another systematic review of the longitudinal population-based studies that investigated the relationship between childhood SES and later alcohol use in adolescents and adults found little evidence to support the association between lower childhood SES and later alcohol use or misuse (Wiles, Lingford-Hughes et al. 2007). Some studies have indicated that a lower SES is associated with more problematic alcohol use (i.e., heavy and binge drinking) among adolescents, whereas, adolescents in higher SES tend to show more occasional and experimental alcohol use (Legleye, Janssen et al. 2013, Sweeting, West 2001). For example, a national survey of adolescents aged 17 living in continental France $(n=29,393)$ has indicated that adolescents from high family-occupational category households were more likely to be experimenters and drinkers during the past month, and those from low familyoccupational categories reported more binge drinking (Legleye, Janssen et al. 2013). In addition, adolescents from farmers' families were at highest risk for frequent use and binge drinking in the previous month (Legleye, Janssen et al. 2013). Other studies have suggested that lower SES somewhat plays a protective role for adolescent drinking. For

This article is protected by copyright. All rights reserved. 
example, a study in Scotland showed that adolescents in a disadvantaged socioeconomic position were less likely to be classified as heavier drinkers relative to their peers (Green, Leyland et al. 2013). Similarly, a national survey of adolescents in Brazil $(n=17,297)$ indicated that the risk of past-year binge drinking among students was increased as SES increased (Sanchez, Locatelli et al. 2013).

Despite the several studies on the relationship between SES and alcohol use among adolescents, the impact of implementing school-based substance use prevention programmes on youth living in different socioeconomic contexts has received little attention. The limited studies in this area have generally been conducted on the evaluation of universal approaches for students in lower SES or minorities (e.g., Vicary, Smith et al. 2006, Hecht, Marsiglia et al. 2003, Botvin, Schinke et al. 1995). Only a few studies have compared the impact of prevention programmes in students in low and high SES. A cluster randomised controlled trial, that investigated the effect of SES of the school environment on the efficacy of a school-based prevention programme (i.e., 12session standardised curriculum based on a comprehensive social influence model) on alcohol use among 12-14 years old European students $(\mathrm{N}=7079)$, found no significant effect for the programme on the frequency of alcohol use and the intention to drink in the whole sample and for any SES subgroup (Caria, Faggiano et al. 2011). However, findings indicated a significant reduction in reporting episodes of drunkenness and intention to get drunk in adolescents who were in schools of low SES at baseline. No significant intervention effect was found for students in schools of medium or high SES (Caria, Faggiano et al. 2011). These findings suggest that comprehensive social influence programmes may have higher preventive impact on reduction of more problematic 
drinking among adolescents living in underprivileged social environments, compared to students living in more affluent context (Caria, Faggiano et al. 2011). Another study on the impact of neighborhood characteristics on efficacy of a randomized trial of a schoolbased substance use prevention programme (i.e., keepin' it REAL) indicated that living in poorer neighbourhoods decreased the effectiveness of this programme against alcohol use among one ethnic subgroup of the study (i.e., linguistically acculturated Latinos) (Yabiku, Kulis et al. 2007). These prevention programmes were generally curriculumbased universal approaches which target all students regardless of their level of risk for substance use. We found only one study that examined the effect of a targeted/selective intervention (i.e., Preventure programme) on alcohol outcomes in youth with different education levels within the Dutch school system (Lammers, Goossens et al. 2017). This study showed that personality-targeted interventions reduced binge drinking, binge drinking frequency, alcohol use and alcohol use frequency in lower educated young adolescents (e.g. vocational training), but not in the higher education group (e.g., preuniversity education) (Lammers, Goossens et al. 2017). However, this study did not account for the socioeconomic characteristics such as economic and social positions at the levels of family, school or neighborhood. Given the critical need to eliminate disparities in health promotion practices, an examination of the effectiveness of preventive community-based programmes for reducing adolescent alcohol use and related harm across different SES is highly relevant.

This article is protected by copyright. All rights reserved. 


\section{Effects of Peer Victimisation on Alcohol Use Prevention programmes}

Another contextual risk factor that plays a role in youth substance use is peer victimisation. There is a vast literature regarding the associations between peer victimisation and adolescent alcohol use (see a review article by Maniglio 2017). A number of studies have suggested that victimised adolescents may use substances to selfmedicate or cope with the negative emotions and memories associated with the victimisation experience (e.g., Danielson, de Arellano et al. 2006, Marschall-Lévesque, Castellanos-Ryan et al. 2017). Other alternative approaches suggest that alcohol use might contribute to the risk of victimisation rather than being a consequence of it (e.g., (Shepherd, Sutherland et al. 2006, Champion, Foley et al. 2004), for instance, by impairing individual's judgement in potentially dangerous and risky situations (Shepherd, Sutherland et al. 2006, Champion, Foley et al. 2004). A third view suggests that common and co-occurring individual (e.g., personality, genetic) and environmental (e.g., childhood maltreatment, school context) risk factors may explain the relationship between peer victimisation and substance use in adolescents (Hong, Espelage 2012, Hong, Davis et al. 2014).

Given the high rates of co-occurrence of peer victimisation and alcohol misuse during adolescence, it is critical to determine whether adolescents exposed to peer victimisation would similarly benefit from the school-based substance use prevention programmes. We did not find any study that examined the effect of peer victimisation on the effectiveness of school-based substance use prevention programmes on reducing alcohol use and related harm among adolescents. The current study sought to address this particular gap in the literature.

This article is protected by copyright. All rights reserved. 


\section{Current Study}

The aim of this study was to examine the moderating effects of two important contextual risk factors (i.e., peer victimisation and SES) on the effectiveness of personality-targeted interventions (i.e., Preventure programme) against adolescent alcohol use outcomes using the longitudinal data from the Adventure cluster-randomised trial (Mahu, Doucet et al. 2015, Conrod, O'Leary-Barrett et al. 2013) in a multilevel analytic framework with a large sample of adolescents $(\mathrm{N}=3021)$.

One reason that may contribute to the inconsistent findings on the associations between SES and adolescent alcohol consumption is the use of different measures for assessment of alcohol outcomes and/or SES (e.g., objective vs. subjective measures) (e.g., Legleye, Janssen et al. 2013, Sweeting, West 2001). The current study assessed SES at both subjective (self-report SES), and objective (i.e., school-level 'Index of Multiple Deprivation (IMD) scores'; Department for Communities and Local Government 2010) levels and also used multiple alcohol use outcomes to ascertain whether SES, examined at the levels of individuals and schools, has an effect on the efficacy of personality-targeted interventions against alcohol use outcomes.

The finding from this study will inform on the potential applicability and benefit of personality-targeted interventions to adolescent groups in different socioeconomic levels and those exposed to peer victimisation.

This article is protected by copyright. All rights reserved. 


\section{Materials and Methods \\ Participants and procedures}

Nineteen secondary schools across 18 London boroughs were recruited to participate in the Adventure cluster-randomised trial, and all grade 9 students attending school in September 2007 were invited to participate $(n=3021)$ (please see Figure 1 for recruitment, selection protocol, and rates). The response rate was $87.5 \%(n=2643)$. The study selected youth who scored high (i.e., one standard deviation above the school mean) on one of the four subscales of the Substance Use Risk Profile Scale (SURPS; Woicik, Stewart et al. 2009). The final study sample consists of 1025 high-risk adolescents (54\% male, mean age 13.7 years at baseline, $43 \%$ white). This sample represents $84.7 \%$ of randomized high-risk participants. The study followed a cluster randomised design in which schools were allocated to intervention or control conditions according to a computerised randomisation procedure. High-risk participants from intervention schools were invited to participate in personality-targeted intervention for which they showed the most statistical deviance according to z-scores (for more information regarding the randomisation of this study, please see O'Leary-Barrett, Mackie et al., 2010, Conrod, O'Leary-Barrett et al. 2013).

Participants were surveyed during class time using self-report questionnaires at 6month intervals for 2 years. To maximize the accuracy of self-reports, visual prompts were used to assess quantity of alcohol consumption, a reliability check (sham drug item) was included, and baseline and follow-up assessments were conducted by research team, rather than school staff.

This article is protected by copyright. All rights reserved. 
Active assent from students and passive consent from parents for both survey and intervention phases were obtained. All high-risk students were included in the intent-totreat analysis regardless of whether or not they received an intervention.

\section{Measures}

Personality Risk Profiles. The 23-item SURPS questionnaire (Woicik, Stewart et al. 2009) was used to assess variation in personality risk for substance abuse and dependence including four different dimensions: Sensation-Seeking, Impulsivity, Anxiety-Sensitivity and Hopelessness (referred to in adolescents as Negative Thinking). The SURPS has good concurrent, predictive and incremental validity in differentiating individuals prone to reinforcement-specific patterns of substance-use (Krank, Stewart et al. 2011, Woicik, Stewart et al. 2009, Castellanos-Ryan, O'Leary-Barrett et al. 2013, Conrod, Pihl et al. 2000). It is concurrently and prospectively associated with substance misuse and nonsubstance-related externalising behaviours and internalising symptoms (Krank, Stewart et al. 2011, Woicik, Stewart et al. 2009, Castellanos-Ryan, O'LearyBarrett et al. 2013), and shows adequate sensitivity and specificity with respect to predicting the majority of youth who will develop substance use and mental health problems, and the types of problems that they develop (Castellanos-Ryan, O'LearyBarrett et al. 2013). In the present sample, each of the subscales had good internal reliability for short scales, with Cronbach $\alpha$ coefficients ranging from .57 to $.79(\alpha=.57$ for sensation seeking [six items], $\alpha=.62$ for anxiety-sensitivity [five items], $\alpha=.68$ for impulsivity [five items], $\alpha=.79$ for hopelessness seven items]) and inter-item correlations

This article is protected by copyright. All rights reserved. 
ranging from 0.19 to 0.35 (0.19 for SS; 0.24 for AS, 0.30 for IMP; 0.35 for H). (O'LearyBarrett, Topper et al. 2013).

Drinking Outcomes. Alcohol use was assessed by asking students to report the quantity and frequency of their alcohol consumption over the past 6-months. Bingedrinking was assessed by asking students how often they had consumed 5 or more alcoholic beverages (4 or more for girls) on one occasion. An alcohol harm score was created using a shortened version of the Rutgers Alcohol Problem Index (RAPI; White, Labouvie 1989). RAPI showed a good internal reliability with the present sample $(\alpha=$ 0.90).

Peer Victimisation. Exposure to peer victimisation was measured using four victimisation items of the 'bullying questionnaire', amended from questions used in the large international study entitled: Health Behaviour in School-aged Children (HBSC) study (Currie, Molcho et al. 2008), which were originally taken from the Revised Olweus Bully/Victim Scale (Olweus 1996). Good internal reliability has been previously reported using the same four items for assessing exposure to peer victimisation in adolescents (Topper, Castellanos-Ryan et al. 2011). In the present study, a good internal reliability was also shown for this measure $(\alpha=0.85)$.

Socioeconomic Status (SES). SES was assessed using items from the Family Affluence Scale for Adolescents (Currie, Elton et al. 1997). Five items included for calculating the SES score were: (1) how much pocket money do you get from your parent

This article is protected by copyright. All rights reserved. 
/guardian each week? (2) how many cars do your family possess? (3) do you have a bedroom of your own? (4) do you have a computer at home? (5) do you regularly go on holiday with your family? This scale has been used in the WHO-Health Behaviour in School-aged Children (HBSC) survey in several countries (Currie, Elton et al. 1997) and has shown a good criterion and construct validity using data from 35 countries (Boyce, Torsheim et al., 2006).

Index of Multiple Deprivation (IMD). We used the Index of Multiple Deprivation (IMD) 2010 scores (Department for Communities and Local Government 2010), which was the most recent available at the time of this study. The IMD is a measure of relative deprivation at small area level (i.e., Lower layer Super Output Area (LSOA)) across England published every three to four years by the Department for Communities and Local Government (Department for Communities and Local Government 2010). According to The English Indices of Deprivation (Department for Communities and Local Government 2010), most of the data used for calculating the 2010 Indices are for the year 2008. The IMD 2010 scores were calculated for every LSOA based on 38 separate indicators, structured across seven domains of deprivation: income deprivation; employment deprivation; health deprivation and disability; education deprivation; crime deprivation; barriers to housing and services deprivation; and living environment deprivation. Areas are ranked from least deprived to most deprived (Department for Communities and Local Government 2010). We used the postcode of all 19 secondary schools recruited for this study across 18 London boroughs to extract the IMD 2010 score and ranking of each school. Schools were categorised into two groups:

This article is protected by copyright. All rights reserved. 
most deprived: top 20\%, and others (Department for Communities and Local Government 2010).

Demographics. Adolescents provided age, gender and ethnicity information.

\section{Intervention}

All interventions were provided at the participants' schools by a trained facilitator and co-facilitator from January to April 2008. After selection on personality scale (i.e., SURPS; Woicik, Stewart et al. 2009), high-risk adolescents were invited to participate in brief group-based intervention sessions which targeted their dominant personality profile. Each intervention involved two 90-minute sessions, with an average of 6 personalitymatched adolescents per group, and was conducted using manuals that incorporate psycho-educational, motivational enhancement therapy (MET), and cognitive behavioural therapy (CBT) components which include real life 'scenarios' shared by high-risk U.K. youth with similar personality profiles. For more information regarding the content of the interventions, please refer to previous publications (e.g., O'LearyBarrett, Mackie et al., 2010, Conrod, O'Leary-Barrett et al. 2013, and a recent review article by Conrod 2016).

This article is protected by copyright. All rights reserved. 


\section{Data Analysis}

Descriptive analyses were conducted using SPSS for Windows, V24.0. We used independent sample t-test and Chi-Square test to examine group differences in baseline characteristics of low-risk vs. high-risk (Intervention vs. Treatment as Usual) adolescent groups.

Multilevel Linear Modelling (MLM) was conducted, using the R statistical software lme 4 package, to assess the moderating effect of baseline peer victimisation and the SES (measured by student's self-report SES and school-level Index of Multiple Deprivation (IMD)). Models included random intercepts for school and individual (time nested in individual nested in school) and controlled for ethnicity (Caucasian vs. Other), gender, and baseline age (sample mean centered). Separate models were estimated to examine the moderating effect of peer victimisation and the SES on intervention for each outcome. Time-invariant predictors (i.e., school/individual level fixed effect predictors) were ethnicity, baseline age (sample mean centered), intervention (i.e., school allocation), and pre-intervention alcohol use, along with baseline victimisation and victimisation by intervention interaction to investigate the moderating effect of peer victimisation, and student's baseline SES/IMD by intervention interaction to investigate the moderating effect of SES/IMD. The time parameter was coded from one to four (i.e., waves, from 6 to 24 months post-intervention). The only level-1 predictors were linear and quadratic effects of time. Normality and homoscedasticity of residuals have been verified for each step of the presented models. No constraints has been applied to random effects/residual covariance matrices. Missing data were replaced using multiple imputations (Mice package in R statistical software), which enabled the use of full dataset.

This article is protected by copyright. All rights reserved. 


\section{Results}

Table 1 presents the baseline characteristics for the total sample and low-risk vs. high-risk (Intervention vs. Treatment as Usual) adolescent groups. Adolescents in highrisk group reported higher SES $(t=3.1, p=.000)$, and showed greater levels of peer victimisation $(t=9.6, p=.000)$ and alcohol outcomes: any drinking $\left(X^{2}=19.1, p=\right.$ $.000)$, any binge drinking $\left(X^{2}=39.4, p=.000\right)$, alcohol use frequency $(t=6.8, p=.000)$, quantity $(t=6.4, p=.000)$, binge drinking frequency $(t=6.8, p=.000)$ and alcoholrelated harm (RAPI score) $(t=7.5, p=.000)$ compared to low-risk group. Among highrisk groups, those in Intervention group indicated a slightly higher level of peer victimisation ( $\mathrm{M}=6.9$ vs. 6.7$)$ compared to adolescents in Treatment as Usual group $(t=$ $1.38, p=.024)$.

'Table 1 here'

Table 2 shows the longitudinal association between SES, intervention and six alcohol outcomes. Four alcohol-related outcomes were associated with SES and IMD. However, there was no significant interaction between intervention status and SES/IMD for any alcohol outcomes. Of total variability in the binary drinking outcome, $68 \%$ was explained by variability between individuals (individual random intercept $=7.92$ ), and $3 \%$ by variability between schools. The unconditional change model indicated a negative yet non-significant linear effect of time and a positive significant quadratic effect of time, suggesting a non-linear pattern of change and accentuated increase in alcohol use in later adolescence. Reporting any drinking in the past 6 month was associated with higher SES $(\beta=.30$, S.E. $=.10, p=0.01)$ and lower school IMD $(\beta=-.51, S . E .=.20, p=0.01)$. Of total variability in the binary binge drinking, $71 \%$ was explained by variability between

This article is protected by copyright. All rights reserved. 
individuals (individual random intercept=14.59), and less than $1 \%$ by variability between schools. The unconditional change model indicated a positive significant linear effect of time and a positive yet non-significant quadratic effect of time. Reporting any binge drinking in the past 6 month was associated with higher SES $(\beta=.29$, S.E. $=.14, p=0.03)$, and lower school IMD ( $\beta=-.79$, S.E.=.28, $p=0.01)$. Of total variability in the quantity of drinking, 64\% was explained by variability between individuals (individual random intercept $=0.82$ ), and less than $1 \%$ by variability between schools. The unconditional change model indicated a positive significant linear effect of time and a positive significant quadratic effect of time. Quantity of drinking was associated with higher SES $(\beta=.05$, S.E. $=.02, p=0.02)$. Of total variability in the frequency of binge drinking, $57 \%$ was explained by variability between individuals (individual random intercept=0.33), and less than $1 \%$ by variability between schools. The unconditional change model indicated a positive yet non-significant linear effect of time and a positive significant quadratic effect of time. Frequency of binge drinking was associated with higher SES ( $\beta=.04$, S.E. $=.02$, $p=0.01)$.

\section{'Table 2 here'}

Table 3 shows the longitudinal association between peer victimisation, intervention and six alcohol outcomes. No significant interaction between intervention status and peer victimisation was found for any alcohol outcome. Alcohol-related harm was the only drinking outcome affected by victimisation. Of total variability in the alcohol-related harm, $41 \%$ was explained by variability between individuals (individual random intercept $=7.77$ ), and less than $0.01 \%$ by variability between schools. The unconditional change model indicated a non-significant effect of time suggesting it 
remained relatively stable across time. Higher alcohol-related harm was observed among those reporting peer victimisation $(\beta=.28, S . E .=.09, p=0.01)$, as well as a significant interaction between peer victimisation and intervention status; alcohol-related harm decreased specifically for students reporting peer victimisation who participated in the intervention workshops $(\beta=-.29$, S.E.=.11, $p=.014$; see Table 3).

'Table 3 here'

\section{Discussion}

This study examined whether contextual risk factors (i.e., peer victimisation and SES) moderate the effect of personality-targeted interventions against adolescent alcohol outcomes using the data from the Adventure cluster-randomised trial (Mahu, Doucet et al. 2015, Conrod, O'Leary-Barrett et al. 2013). Results indicated that high-risk adolescents exposed to peer victimisation and those in different socioeconomic levels would equally benefit from this intervention approach with regards to reducing their alcohol outcomes and related harm.

Consistent with some previous studies (Sanchez, Locatelli et al. 2013, Green, Leyland et al. 2013), the present study indicated that adolescents who reported higher SES showed higher baseline levels of alcohol consumption and related harm compared to youth with lower SES. However, they did not respond differently to the intervention despite their initial higher levels of alcohol consumption and related harm and similarly benefited from the interventions. Result from previous studies on evaluation of schoolbased prevention programmes have been limited to students in lower socioeconomic contexts (Vicary, Smith et al. 2006, Botvin, Schinke et al. 1995, Hecht, Marsiglia et al.

This article is protected by copyright. All rights reserved. 
2003) or found either a weaker (Yabiku, Kulis et al. 2007) or stronger (Caria, Faggiano et al. 2011) influence for students in lower SES when compared groups in different socioeconomic levels. These prevention programmes were generally curriculum-based universal approaches which target all students regardless of their level of risk for substance use. Personality-targeted interventions, on the other hand, target high-risk youth based on their personality risk profiles and is designed to work independent of educational resources or/and familial and social support, which might be limited in disadvantaged neighborhood. In addition, the present study investigated socioeconomic characteristics at subjective individual and objective school levels, and also objective level (i.e., IMD scores) in a multilevel analytic framework to further explain contextual disparities in alcohol consumption and related harm. Altogether, the content of personality-targeted interventions appeared to be relevant to students' individual risk and be beneficial for all high-risk youth regardless of their socioeconomic strata or school neighborhood.

Interventions were also equally beneficial for adolescents exposed to peer victimisation in terms of their alcohol consumption and related harm, despite the fact they had higher rates of ever drinking, binge drinking, and alcohol-related harm at baseline. In particular, interventions appeared to significantly reduce the rate of alcohol-related harm in victimised adolescents compared to non-victimised youth. Evidence shows that victims of peer victimisation are at increased risk of substance misuse (See Maniglio 2017). Whether this relationship is direct (causation (Danielson, de Arellano et al. 2006)) or indirect (mediated by other factors such as depression and anxiety; Earnshaw, Elliott et al. 2017, Lui, Sterling et al. 2017), personality-targeted interventions appeared to reduce

This article is protected by copyright. All rights reserved. 
the rates of alcohol use among victimised adolescents similar to their non-victimised peers. The current findings indicated that personality-targeted interventions can provide an opportunity to deliver effective substance use interventions at school level for the atrisk victimised adolescents even if the peer victimisation is unrecognised by teachers and parents. In particular, receiving intervention was additionally beneficial for adolescents with higher levels of peer victimisation which suggests a protective effect in these adolescents who already indicated a higher risk of alcohol-related harm at baseline.

This study is not without limitations. First, we have used self-report measures for assessment of alcohol use outcomes and peer victimisation. Our assessment did not involve more objective methods of measuring these behaviours, such as nominating by peers for peer victimisation. Because of the sensitive nature of reporting these behaviours, they might have been underreported. However, this study has utilised several methods to maximize the accuracy and reliability of self-report data, including those explained in Methods section. Second, we used postcode of schools for placing them in two deprivation groups based on the IMD 2010 (Department for Communities and Local Government 2010) ranking. It might be possible that students in a certain school lived in a different area and have a different deprivation ranking based on their place of residence. However, because of the "catchment areas", students are only eligible to attend their local schools, and therefore, it is reasonable to assume that most students lived close to their schools (at least for the public/government schools). Finally, we did not examine for the impact of other contextual risk factors, such as peer group and parenting style, which might influence the effectiveness of personality-targeted interventions on alcohol outcomes.

This article is protected by copyright. All rights reserved. 


\section{Conclusion}

Together, the current study suggests that using targeted approaches, such as targeting underlying personality risk factors, may be the most appropriate substance use prevention strategy for at-risk youth, as it is beneficial for all at-risk youth regardless of their contextual risk factors. This is the first study which examined whether adolescents exposed to peer victimisation and those in different SES would equally benefit from the personality-targeted approach and one of the few studies to evaluate the impact of peer victimisation and different socioeconomic levels on the effectiveness of a school-based preventive programme against multiple alcohol outcomes. Using an intent-to-treat analysis, long-term and multiple follow-ups allowing measurement of intervention effects over an extended period, and statistical methods that capture SES at both subjective and objective levels are of other strengths of this study. Future studies are needed to examine the impact of other contextual risk factors (e.g., peer group and parenting style) on the effectiveness of school-based preventive programmes including personality-targeted interventions for reducing adolescent substance use problems.

\section{References}

BOTVIN, G.J., BAKER, E., DUSENBURY, L., TORTU, S. and BOTVIN, E.M., 1990. Preventing adolescent drug abuse through a multimodal cognitive-behavioral approach: results of a 3-year study. Journal of consulting and clinical psychology, 58(4), pp. 437-446.

This article is protected by copyright. All rights reserved. 
BOTVIN, G.J., SCHINKE, S.P., EPSTEIN, J.A., DIAZ, T. and BOTVIN, E.M., 1995. Effectiveness of culturally focused and generic skills training approaches to alcohol and drug abuse prevention among minority adolescents: Two-year followup results. Psychology of Addictive Behaviors, 9(3), pp. 183-194.

BOYCE, W., TORSHEIM, T., CURRIE, C., and ZAMBON, A., 2006. The family affluence scale as a measure of national wealth: validation of an adolescent selfreport measure. Social Indicators Research, 78, pp. 473-487.

CARIA, M.P., FAGGIANO, F., BELLOCCO, R. and GALANTI, M.R., 2011. The influence of socioeconomic environment on the effectiveness of alcohol prevention among European students: a cluster randomized controlled trial. $B M C$ public health, 11 (312).

CASTELLANOS-RYAN, N., O'LEARY-BARRETT, M., SULLY, L. and CONROD, P.J., 2013. Sensitivity and specificity of a brief personality screening instrument in predicting future substance use, emotional, and behavioral problems: 18-month predictive validity of the Substance Use Risk Profile Scale. Alcoholism, Clinical and Experimental Research, 37 Suppl 1, pp. E281-90.

CHAMPION, H.L.O., FOLEY, K.L., DURANT, R.H., HENSBERRY, R., ALTMAN, D. and WOLFSON, M., 2004. Adolescent sexual victimization, use of alcohol and other substances, and other health risk behaviors. Journal of Adolescent Health, 35(4), pp. 321-328.

CONROD, P.J. and NIKOLAOU, K., 2016. Annual Research Review: On the developmental neuropsychology of substance use disorders. Journal of child psychology and psychiatry, and allied disciplines, 57(3), pp. 371-394.

This article is protected by copyright. All rights reserved. 
CONROD, P.J., 2016. Personality-Targeted Interventions for Substance Use and Misuse. Current addiction reports, $\mathbf{3}(4)$, pp. 426-436.

CONROD, P.J., O'LEARY-BARRETT, M., NEWTON, N., TOPPER, L., CASTELLANOS-RYAN, N., MACKIE, C. and GIRARD, A., 2013. Effectiveness of a selective, personality-targeted prevention program for adolescent alcohol use and misuse: a cluster randomized controlled trial. JAMA psychiatry, 70(3), pp. 334-342.

CONROD, P.J., PIHL, R.O., STEWART, S.H. and DONGIER, M., 2000. Validation of a system of classifying female substance abusers on the basis of personality and motivational risk factors for substance abuse. Psychology of addictive behaviors: journal of the Society of Psychologists in Addictive Behaviors, 14(3), pp. 243-256.

CUIJPERS, P., 2002. Effective ingredients of school-based drug prevention programs. A systematic review. Addictive Behaviors, 27(6), pp. 1009-1023.

CURRIE, C., ELTON, R.A., TODD, J. and PLATT, S., 1997. Indicators of socioeconomic status for adolescents: the WHO Health Behaviour in School-aged Children Survey. Health education research, 12(3), pp. 385-397.

CURRIE, C., MOLCHO, M., BOYCE, W., HOLSTEIN, B., TORSHEIM, T. and RICHTER, M., 2008. Researching health inequalities in adolescents: the development of the Health Behaviour in School-Aged Children (HBSC) family affluence scale. Social science \& medicine (1982), 66(6), pp. 1429-1436.

DANIELSON, C.K., DE ARELLANO, M.A., EHRENREICH, J.T., SUAREZ, L.M., BENNETT, S.M., CHERON, D.M., GOLDSTEIN, C.R., JAKLE, K.R.,

This article is protected by copyright. All rights reserved. 
LANDON, T.M. and TROSPER, S.E., 2006. Identification of high-risk behaviors among victimized adolescents and implications for empirically supported psychosocial treatment. Journal of psychiatric practice, 12(6), pp. 364-383.

DEPARTMENT FOR COMMUNITIES AND LOCAL GOVERNMENT, 2010. The English Indices of Deprivation. Statistical release; March 2011, .

DISHION, T.J. and ANDREWS, D.W., 1995. Preventing escalation in problem behaviors with high-risk young adolescents: immediate and 1-year outcomes. Journal of consulting and clinical psychology, 63(4), pp. 538-548.

EARNSHAW, V.A., ELLIOTT, M.N., REISNER, S.L., MRUG, S., WINDLE, M., EMERY, S.T., PESKIN, M.F. and SCHUSTER, M.A., 2017. Peer Victimization, Depressive Symptoms, and Substance Use: A Longitudinal Analysis. Pediatrics, .

EDALATI, H. and CONROD, P.J., 2017. A Review to Identify Gaps in Research and Service Delivery for Substance Use Prevention among At-risk Adolescents Involved in Child Welfare System: The Promises of Targeted Interventions. International Journal of Child and Adolescent Resilience, 5(1), pp. 20-39.

ELLICKSON, P. and BELL, R., 1990. Prospects for Preventing Drug Use Among Young Adolescents. . Santa Monica, CA: RAND Corporation.

FOXCROFT, D.R. and TSERTSVADZE, A., 2011. Universal family-based prevention programs for alcohol misuse in young people. The Cochrane database of systematic reviews, (9):CD009308. doi(9), pp. CD009308.

GOTTFREDSON, D.C. and WILSON, D.B., 2003. Characteristics of effective schoolbased substance abuse prevention. Prevention science: the official journal of the Society for Prevention Research, 4(1), pp. 27-38.

This article is protected by copyright. All rights reserved. 
GREEN, M.J., LEYLAND, A.H., SWEETING, H. and BENZEVAL, M., 2013.

Socioeconomic position and adolescent trajectories in smoking, drinking, and psychiatric distress. The Journal of adolescent health: official publication of the Society for Adolescent Medicine, 53(2), pp. 202-208.e2.

HANSON, M.D. and CHEN, E., 2007. Socioeconomic status and health behaviors in adolescence: a review of the literature. Journal of Behavioral Medicine, 30(3), pp. 263-285.

HARRINGTON, N.G. and DONOHEW, L., 1997. Jump start: a targeted substance abuse prevention program. Health education \& behavior: the official publication of the Society for Public Health Education, 24(5), pp. 568-586.

HECHT, M.L., MARSIGLIA, F.F., ELEK, E., WAGSTAFF, D.A., KULIS, S., DUSTMAN, P. and MILLER-DAY, M., 2003. Culturally grounded substance use prevention: an evaluation of the keepin' it R.E.A.L. curriculum. Prevention science: the official journal of the Society for Prevention Research, 4(4), pp. 233248.

HONG, J.S., DAVIS, J.P., STERZING, P.R., YOON, J., CHOI, S. and SMITH, D.C., 2014. A conceptual framework for understanding the association between school bullying victimization and substance misuse. The American Journal of Orthopsychiatry, 84(6), pp. 696-710.

HONG, J.S. and ESPELAGE, D.L., 2012. A review of research on bullying and peer victimization in school: An ecological system analysis. Aggression and Violent Behavior, 17(4), pp. 311-322.

This article is protected by copyright. All rights reserved. 
KRANK, M.D., STEWART, S.H., O'CONNOR, R., WOICIK, P.B., WALL, A. and CONROD, P.J., 2011. Structural, concurrent, and predictive validity of the Substance Use Risk Profile Scale in early adolescence. Addictive Behaviors, 36(1-2), pp. 37-46.

LAMMERS, J., GOOSSENS, F., CONROD, P., ENGELS, R., WIERS, R.W. and KLEINJAN, M., 2017. Effectiveness of a selective alcohol prevention program targeting personality risk factors: Results of interaction analyses. Addictive Behaviors, 71, pp. 82-88.

LEGLEYE, S., JANSSEN, E., SPILKA, S., LE NEZET, O., CHAU, N. and BECK, F., 2013. Opposite social gradient for alcohol use and misuse among French adolescents. The International journal on drug policy, 24(4), pp. 359-366.

LUI, C.K., STERLING, S.A., CHI, F.W., LU, Y. and CAMPBELL, C.I., 2017. Socioeconomic differences in adolescent substance abuse treatment participation and long-term outcomes. Addictive Behaviors, 68, pp. 45-51.

MAHU, I.T., DOUCET, C., O'LEARY-BARRETT, M. and CONROD, P.J., 2015. Can cannabis use be prevented by targeting personality risk in schools? Twenty-fourmonth outcome of the adventure trial on cannabis use: a cluster-randomized controlled trial. Addiction (Abingdon, England), 110(10), pp. 1625-1633.

MANIGLIO, R., 2017. Bullying and Other Forms of Peer Victimization in Adolescence and Alcohol Use. Trauma, violence \& abuse, 18(4), pp. 457-473.

This article is protected by copyright. All rights reserved. 
MARSCHALL-LÉVESQUE, S., CASTELLANOS-RYAN, N., PARENT, S., RENAUD, J., VITARO, F., BOIVIN, M., TREMBLAY, R.E. and SÉGUIN, J.R., 2017. Victimization, Suicidal Ideation, and Alcohol Use From Age 13 to 15 Years: Support for the Self-Medication Model.

O'LEARY-BARRETT, M., CASTELLANOS-RYAN, N., PIHL, R.O. and CONROD, P.J., 2016. Mechanisms of personality-targeted intervention effects on adolescent alcohol misuse, internalizing and externalizing symptoms. Journal of consulting and clinical psychology, 84(5), pp. 438-452.

O'LEARY-BARRETT, M., MACKIE, C.J., CASTELLANOS-RYAN, N., AlKHUDHAIRY, N., and CONROD, P.J., 2010. Personality-targeted interventions delay uptake of drinking and decrease risk of alcohol-related problems when delivered by teachers. Journal of American Academy of Child and Adolescent Psychiatry, 49(9), pp. 954-63.

O'LEARY-BARRETT, M., TOPPER, L., Al-KHUDHAIRY, N., PIHL, R.O. CASTELLANOS-RYAN, N., MACKIE, C.J., and CONROD, P.J., 2013. Twoyear impact of personality-targeted, teacher-delivered interventions on youth internalizing and externalizing problems: a cluster-randomized trial. Journal of American Academy of Child and Adolescent Psychiatry, 52(9), pp. 911-20. OLWEUS, D., 1996. Bully/victim problems in school. Prospects, 26(2), pp. 331359.

PERRIER-MENARD, E., CASTELLANOS-RYAN, N., O'LEARY-BARRETT, M., GIRARD, A. and CONROD, P.J., 2017. The impact of youth internalising and externalising symptom severity on the effectiveness of brief personality-targeted

This article is protected by copyright. All rights reserved. 
interventions for substance misuse: A cluster randomised trial. Addictive Behaviors, 75, pp. 138-144.

SANCHEZ, Z.M., LOCATELLI, D.P., NOTO, A.R. and MARTINS, S.S., 2013. Binge drinking among Brazilian students: a gradient of association with socioeconomic status in five geo-economic regions. Drug and alcohol dependence, 127(1-3), pp. 87-93.

SHEPHERD, J.P., SUTHERLAND, I. and NEWCOMBE, R.G., 2006. Relations between alcohol, violence and victimization in adolescence. Journal of adolescence, 29(4), pp. 539-553.

SWEETING, H. and WEST, P., 2001. Social class and smoking at age 15: the effect of different definitions of smoking. Addiction (Abingdon, England), 96(9), pp. 13571359.

TOBLER, N., ROONA, M., OCHSHORN, P., MARSHALL, D., STREKE, A. and STACKPOLE, K., 2000. School-based adolescent drug prevention programs: 1998 meta-analysis. The Journal of Primary Prevention, 20(4), pp. 275-336.

TOPPER, L.R., CASTELLANOS-RYAN, N., MACKIE, C. and CONROD, P.J., 2011. Adolescent bullying victimisation and alcohol-related problem behaviour mediated by coping drinking motives over a 12 month period. Addictive Behaviors, 36(1-2), pp. 6-13.

VICARY, J.R., SMITH, E.A., SWISHER, J.D., HOPKINS, A.M., ELEK, E., BECHTEL, L.J. and HENRY, K.L., 2006. Results of a 3-year study of two methods of delivery of life skills training. Health education \& behavior: the official publication of the Society for Public Health Education, 33(3), pp. 325-339.

This article is protected by copyright. All rights reserved. 
WHITE, H.R. and LABOUVIE, E.W., 1989. Towards the assessment of adolescent problem drinking. Journal of studies on alcohol, 50(1), pp. 30-37.

WILES, N.J., LINGFORD-HUGHES, A., DANIEL, J., HICKMAN, M., FARRELL, M., MACLEOD, J., HAYNES, J.C., SKAPINAKIS, P., ARAYA, R. and LEWIS, G., 2007. Socio-economic status in childhood and later alcohol use: a systematic review. Addiction (Abingdon, England), 102(10), pp. 1546-1563.

WOICIK, P.A., STEWART, S.H., PIHL, R.O. and CONROD, P.J., 2009. The Substance Use Risk Profile Scale: a scale measuring traits linked to reinforcement-specific substance use profiles. Addictive Behaviors, 34(12), pp. 1042-1055.

YABIKU, S., KULIS, S., MARSIGLIA, F.F., LEWIN, B., NIERI, T. and HUSSAINI, S., 2007. Neighborhood effects on the efficacy of a program to prevent youth alcohol use. Substance use \& misuse, 42(1), pp. 65-87.

This article is protected by copyright. All rights reserved. 
Table 1. Baseline Characteristics for the Low-Risk and High-Risk (Intervention and Treatment as Usual) Groups

\begin{tabular}{|c|c|c|c|c|c|}
\hline \multirow[t]{2}{*}{ Variable } & \multirow[t]{2}{*}{ Total } & \multirow[t]{2}{*}{ Low-Risk $^{\text {a }}$} & \multicolumn{3}{|c|}{ High-Risk $^{\mathrm{b}}$} \\
\hline & & & Total & Intervention & Treatment as Usual \\
\hline $\mathrm{N}$ & 2643 & 1433 & 1210 & 574 & 636 \\
\hline Gender, \% Male & 58 & 59 & 57 & 54 & 60 \\
\hline Ethnicity, \% Caucasian & 42 & 41 & 43 & 41 & 45 \\
\hline $\operatorname{SES}^{\mathrm{c}}$ (Mean) & 7.8 & 7.7 & $7.9^{* *}$ & 7.9 & 8.0 \\
\hline$<8(\%)$ & 49 & 51 & 46 & 47 & 44 \\
\hline$\geq 8(\%)$ & 51 & 49 & 54 & 53 & 56 \\
\hline Victimisation ${ }^{\mathrm{c}}$ (Mean) & 6.2 & 5.7 & $6.8 * *$ & 6.9 & $6.7 *$ \\
\hline$\leq 5(\%)$ & 54 & 62 & 44 & 44 & 45 \\
\hline$>5(\%)$ & 46 & 38 & 56 & 56 & 55 \\
\hline \multicolumn{6}{|l|}{ Baseline Alcohol Outcomes } \\
\hline Drinking (Yes) \% & 37 & 34 & $42 * *$ & 40 & 43 \\
\hline Binge Drinking (Yes) \% & 17 & 13 & $22 * *$ & 21 & 23 \\
\hline Drinking Frequency (Mean) & 1.7 & 1.6 & $1.8 * *$ & 1.8 & 1.9 \\
\hline Drinking Quantity (Mean) & 1.6 & 1.4 & $1.7 * *$ & 1.6 & 1.7 \\
\hline Binge Drinking Frequency (Mean) & 1.3 & 1.2 & $1.4^{* *}$ & 1.4 & 1.4 \\
\hline RAPI (Mean) & 9.5 & 9.0 & $10.1 * *$ & 10.1 & 10.0 \\
\hline
\end{tabular}

$* P<.05, * * P<.001$

Note.

a. Adolescents who had consented to the study protocol but who did not meet personality risk criteria and, therefore, were not randomised to the Intervention Conditions (55\% of the year 9 population).

b. Adolescents who scored one standard deviation above the school mean on one of the Subscales of Substance Use Risk Profile

Scale and were randomised to either Intervention or Treatment as Usual conditions (45\% of the year 9 population).

c. Dichotomised based on median value

This article is protected by copyright. All rights reserved. 
Table 2. Longitudinal association between socioeconomic status, intervention, and six alcohol outcomes in high risk adolescents.

\begin{tabular}{|c|c|c|c|c|c|c|c|c|c|c|c|c|c|c|c|c|c|c|}
\hline Outcome & Dri & (yes $/ n c$ & & & ge (yes) & & Drin & (Frequ & $n c y)$ & & (Quan & ity) & Bing & (Frequ & $n c y)$ & & Harm & \\
\hline Estimate & $\beta$ & S.E. & $\mathrm{p}$ & $\beta$ & S.E. & $\mathrm{p}$ & $\beta$ & S.E. & $\mathrm{p}$ & $\beta$ & S.E. & $\mathrm{p}$ & $\beta$ & S.E. & $\mathrm{p}$ & $\bar{\beta}$ & S.E. & $\mathrm{p}$ \\
\hline (Intercept) & -1.792 & 0.255 & 0.001 & $\begin{array}{c}- \\
4.811\end{array}$ & 0.368 & 0.001 & 1.652 & 0.058 & 0.001 & 1.475 & 0.056 & 0.001 & 1.285 & 0.041 & 0.001 & 9.341 & 0.244 & 0.001 \\
\hline Time & -0.083 & 0.162 & 0.610 & 0.425 & 0.200 & 0.033 & 0.026 & 0.036 & 0.460 & 0.071 & 0.034 & 0.037 & 0.021 & 0.026 & 0.410 & 0.026 & 0.164 & 0.875 \\
\hline Time $^{\wedge} 2$ & 0.113 & 0.032 & 0.001 & 0.044 & 0.039 & 0.256 & 0.017 & 0.007 & 0.013 & 0.015 & 0.007 & 0.026 & 0.011 & 0.005 & 0.027 & 0.061 & 0.032 & 0.057 \\
\hline Socioeconomic Status & 0.301 & 0.096 & 0.002 & 0.288 & 0.136 & 0.034 & 0.047 & 0.024 & 0.051 & 0.054 & 0.023 & 0.019 & 0.040 & 0.016 & 0.014 & 0.175 & 0.092 & 0.057 \\
\hline$I M D$ & -0.513 & 0.196 & 0.009 & $\begin{array}{c}- \\
0.787\end{array}$ & 0.276 & 0.004 & $\begin{array}{c}- \\
0.066\end{array}$ & 0.050 & 0.180 & $\begin{array}{c}- \\
0.069\end{array}$ & 0.048 & 0.149 & 0.025 & 0.033 & 0.456 & 0.198 & 0.189 & 0.295 \\
\hline Intervention & -0.624 & 0.169 & 0.001 & $\begin{array}{c}- \\
0.681\end{array}$ & 0.233 & 0.003 & $\stackrel{-}{0.094}$ & 0.042 & 0.026 & $\begin{array}{c}- \\
0.053\end{array}$ & 0.040 & 0.188 & 0.036 & 0.028 & 0.208 & 0.009 & 0.161 & 0.954 \\
\hline Ethnicity & 1.707 & 0.130 & 0.001 & 2.514 & 0.192 & 0.001 & 0.483 & 0.032 & 0.001 & 0.455 & 0.031 & 0.001 & 0.309 & 0.021 & 0.001 & 1.176 & 0.120 & 0.001 \\
\hline Female & -0.154 & 0.120 & 0.200 & $\overline{-}$ & 0.169 & 0.001 & $\overline{0.141}$ & 0.030 & 0.001 & $\overline{-}$ & 0.029 & 0.001 & $\overline{-}$ & 0.020 & 0.001 & $\overline{0.543}$ & 0.115 & 0.001 \\
\hline Age & 0.163 & 0.059 & 0.006 & 0.210 & 0.084 & 0.012 & 0.022 & 0.015 & 0.134 & 0.030 & 0.014 & 0.039 & 0.029 & 0.010 & 0.005 & 0.080 & 0.057 & 0.163 \\
\hline Pre-intervention drinking & 3.708 & 0.157 & 0.001 & 5.678 & 0.321 & 0.001 & 0.560 & 0.016 & 0.001 & 0.556 & 0.015 & 0.001 & 0.325 & 0.011 & 0.001 & 1.424 & 0.059 & 0.001 \\
\hline Socioeconomic $*$ Intervention & -0.012 & 0.130 & 0.928 & $\begin{array}{c}- \\
0.078\end{array}$ & 0.184 & 0.671 & $\begin{array}{c}- \\
0.019\end{array}$ & 0.033 & 0.567 & $\begin{array}{c}- \\
0.007\end{array}$ & 0.032 & 0.824 & $\begin{array}{c}- \\
0.010\end{array}$ & 0.022 & 0.648 & 0.028 & 0.126 & 0.822 \\
\hline IMD*Intervention & 0.103 & 0.255 & 0.687 & $\begin{array}{c}- \\
0.042\end{array}$ & 0.365 & 0.908 & $\begin{array}{c}- \\
0.030\end{array}$ & 0.064 & 0.643 & $\begin{array}{c}- \\
0.055\end{array}$ & 0.062 & 0.375 & $\begin{array}{c}- \\
0.062\end{array}$ & 0.044 & 0.157 & $\begin{array}{c}- \\
0.381\end{array}$ & 0.247 & 0.123 \\
\hline$I M D * S E S *$ Intervention & 0.087 & 0.170 & 0.607 & 0.288 & 0.250 & 0.250 & 0.035 & 0.043 & 0.412 & 0.026 & 0.042 & 0.538 & $\begin{array}{c}- \\
0.005 \\
\end{array}$ & 0.029 & 0.873 & $\begin{array}{c}- \\
0.125 \\
\end{array}$ & 0.165 & 0.451 \\
\hline
\end{tabular}

This article is protected by copyright. All rights reserved. 
Table 3. Longitudinal association between peer victimisation, intervention, and six alcohol outcomes.

\begin{tabular}{|c|c|c|c|c|c|c|c|c|c|c|c|c|c|c|c|c|c|c|}
\hline Outcome & & $k(y e s)$ & & & ge (yes) & & Drin & (Frequ & ncy) & $D r i$ & k (Quar & ity) & Bing & (Freq & ncy) & & Harm & \\
\hline Estimate & $\beta$ & S.E. & $p$ & $\beta$ & S.E. & $p$ & $\beta$ & S.E. & $p$ & $\beta$ & S.E. & $p$ & $\beta$ & S.E. & $p$ & $\beta$ & S.E. & $p$ \\
\hline (Intercept) & -2.166 & 0.223 & 0.001 & $\begin{array}{c}- \\
5.523\end{array}$ & 0.346 & 0.001 & 1.602 & 0.050 & 0.001 & 1.424 & 0.048 & 0.001 & 1.262 & 0.035 & 0.001 & .433 & 0.213 & 0.001 \\
\hline Time & -0.091 & 0.161 & 0.571 & 0.447 & 0.199 & 0.025 & 0.026 & 0.035 & 0.456 & 0.072 & 0.034 & 0.033 & 0.021 & 0.025 & 0.409 & 0.049 & 0.162 & 0.765 \\
\hline $\operatorname{Time}^{\wedge} 2$ & 0.114 & 0.032 & 0.001 & 0.042 & 0.039 & 0.279 & 0.017 & 0.007 & 0.013 & 0.015 & 0.007 & 0.028 & 0.011 & 0.005 & 0.025 & 0.057 & 0.032 & 0.076 \\
\hline Victmization & 0.068 & 0.105 & 0.517 & $\begin{array}{c}- \\
0.037\end{array}$ & 0.147 & 0.801 & -0.004 & 0.025 & 0.871 & 0.040 & 0.024 & 0.104 & 0.014 & 0.017 & 0.424 & 0.283 & .097 & 0.004 \\
\hline Intervention & -0.483 & 0.121 & 0.001 & $\begin{array}{c}- \\
0.488\end{array}$ & 0.172 & 0.005 & -0.083 & 0.030 & 0.006 & $\begin{array}{c}- \\
0.054\end{array}$ & 0.029 & 0.060 & -0.048 & 0.020 & 0.018 & $\begin{array}{c}- \\
0.184\end{array}$ & 0.115 & 0.111 \\
\hline Ethnicity & 1.789 & 0.130 & 0.001 & 2.733 & 0.194 & 0.001 & 0.496 & 0.031 & 0.001 & 0.468 & 0.030 & 0.001 & 0.320 & 0.021 & 0.001 & 1.165 & 0.116 & 0.001 \\
\hline Female & -0.105 & 0.120 & 0.383 & $\begin{array}{c}- \\
0.730\end{array}$ & 0.170 & 0.001 & -0.128 & 0.030 & 0.001 & $\begin{array}{c}- \\
0.083\end{array}$ & 0.029 & 0.004 & -0.108 & 0.020 & 0.001 & $\begin{array}{c}- \\
0.510\end{array}$ & 0.114 & 0.001 \\
\hline Age & 0.169 & 0.059 & 0.004 & 0.234 & 0.084 & 0.006 & 0.024 & 0.015 & 0.096 & 0.033 & 0.014 & 0.020 & 0.032 & 0.010 & 0.001 & 0.097 & 0.056 & 0.084 \\
\hline Pre-intervention drinking & 3.879 & 0.158 & 0.001 & 6.011 & 0.336 & 0.001 & 0.574 & 0.016 & 0.001 & 0.571 & 0.015 & 0.001 & 0.332 & 0.010 & 0.001 & 1.431 & 0.059 & 0.001 \\
\hline Victmization $*$ Intervention & 0.014 & 0.128 & 0.915 & 0.072 & 0.179 & 0.690 & 0.020 & 0.031 & 0.511 & $\begin{array}{c}- \\
0.034\end{array}$ & 0.030 & 0.249 & -0.018 & 0.021 & 0.396 & $\overline{-} . \overline{292}$ & 0.119 & 0.014 \\
\hline
\end{tabular}

This article is protected by copyright. All rights reserved. 


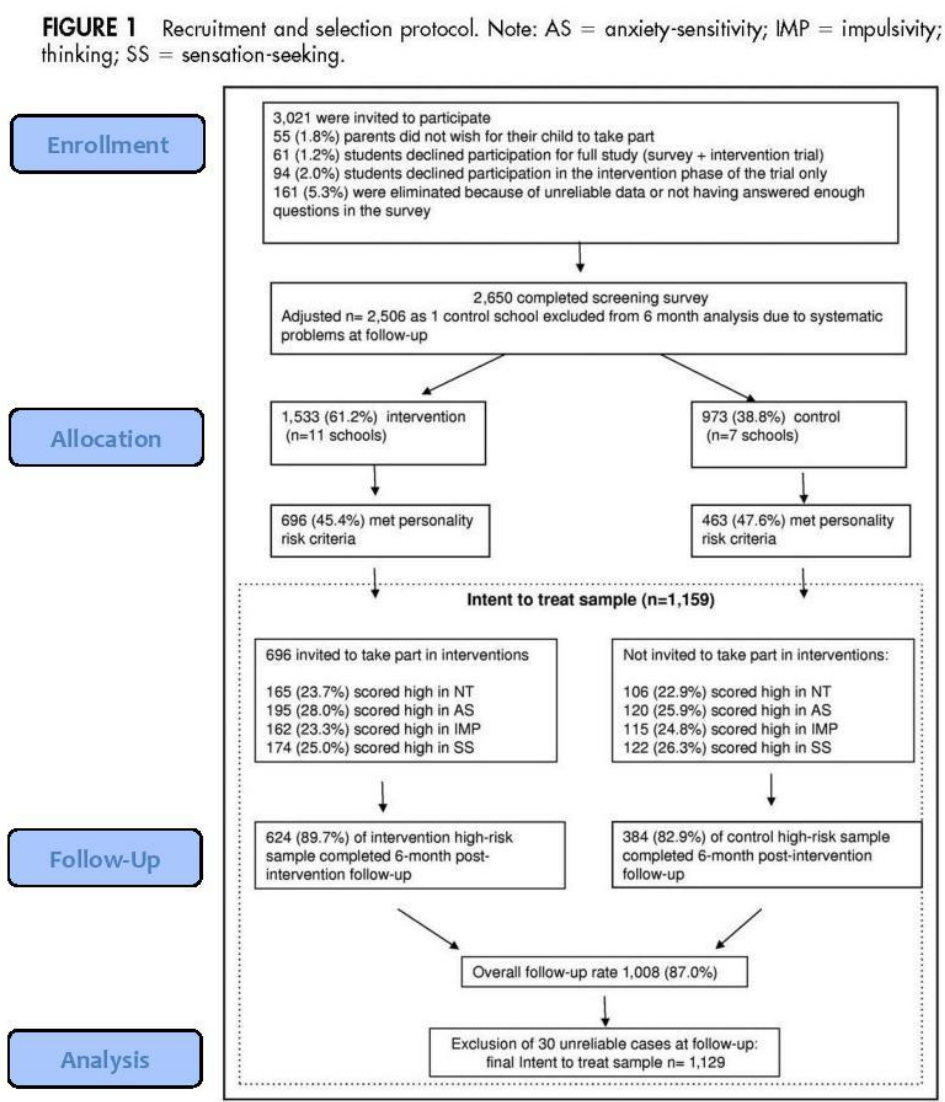

Adapted from O’Leary-Barrett, Mackie et al. 2010

This article is protected by copyright. All rights reserved. 